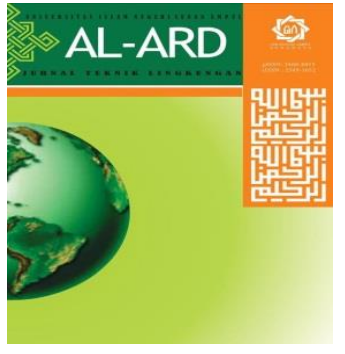

AL-ARD: JURNAL TEKNIK LINGKUNGAN

AL-ARD

Vol.4 No.1 - September 2018 (01-10)

JURNAL

TEKNIK LINGKUNGAN

www.al-ard.uinsby.ac.id

\title{
PEMANFAATAN SAMPAH PLASTIK DAN ORGANIK DALAM PEMBUATAN PAVING BLOCK MENGGUNAKAN MESIN PRESS
}

\author{
Zacky Ubaidillah ${ }^{1}$, Jojo Sumarjo ${ }^{2}$, Eri Widianto ${ }^{3}$, Rizal Hanifi ${ }^{4}$ \\ ${ }^{1}$ Universitas Singaperbangsa Karawang, Karawang, Indonesia \\ zackyubaidillah96@gmail.com \\ 2 Universitas Singaperbangsa Karawang, Karawang, Indonesia \\ eri.widi46@gmail.com \\ ${ }^{3}$ Universitas Singaperbangsa Karawang, Karawang, Indonesia \\ jojosumarjo@gmail.com \\ ${ }^{4}$ Universitas Singaperbangsa Karawang, Karawang, Indonesia \\ rizal.hanifi.rh@gmail.com
}

\begin{abstract}
Research has been done on the manufacture and testing of paving blocks with plastic and organic waste materials using a press machine. The purpose of this study is to determine the compressive strength of paving blocks and as a solution for handling waste around us. The results of manual making paving block research with $100 \%$ plastic waste, the highest value was $110.4 \mathrm{~kg} / \mathrm{cm}^{2}$ and the lowest was $42.2 \mathrm{~kg} / \mathrm{cm}^{2}$ and the highest organic mixture was $99.8 \mathrm{~kg} / \mathrm{cm}^{2}$ and the lowest was $56.0 \mathrm{~kg} / \mathrm{cm}^{2}$. Whereas in the masinal pembutan produce value with $100 \%$ plastic waste $113,9 \mathrm{~kg} / \mathrm{cm}^{2}$ the lowest value $78,4 \mathrm{~kg} / \mathrm{cm}^{2}$. Paving blocks with plastic waste materials are in accordance with SNI quality qualifications.

Keywords: plastic waste, organic mixture, paving block, hard test press, machine press.
\end{abstract}

\begin{abstract}
Abstrak
Telah dilakukan penelitian tentang pembuatan dan pengujian paving block dengan bahan sampah platik dan organik menggunakan mesin press. Tujuan dari penelitian ini untuk mengetahui nilai kuat tekan paving block dan sebagai solusi penanganan sampah disekitar kita. Hasil dari penelitan paving block pembuatan manual dengan $100 \%$ sampah plastik, nilai tertinggi $110,4 \mathrm{~kg} / \mathrm{cm}^{2}$ dan terendah $42,2 \mathrm{~kg} / \mathrm{cm}^{2}$ dan pada campuran organik nilai tertinggi $99,8 \mathrm{~kg} / \mathrm{cm}^{2}$ dan terendah $56,0 \mathrm{~kg} / \mathrm{cm}^{2}$. Sedangkan pada pembutan masinal menghasilkan nilai dengan $100 \%$ sampah plastik $113,9 \mathrm{~kg} / \mathrm{cm}^{2}$ nilai terendah $78,4 \mathrm{~kg} / \mathrm{cm}^{2}$. Paving block dengan bahan sampah plastik sudah sesuai dengan kualifikasi mutu SNI.

Kata Kunci: sampah plastic, sampah organic, paving block, uji kuat tekan, mesin press.
\end{abstract}

\section{PENDAHULUAN}

Pengelolaan sampah di Indonesia masih merupakan permasalahan yang belum dapat ditangani dengan baik. Kegiatan pengurangan sampah baik di masyarakat sebagai penghasil sampah maupun di tingkat kawasan masih sekitar 5\% sehingga sampah tersebut dibuang ke Tempat Pemrosesan Akhir (TPA) sementara lahan TPA tersebut sangat terbatas. Komposisi sampah terbesar di TPA selain sampah organik (70\%) terdapat sampah non organik yaitu sampah plastik (14\%). Limbah padat merupakan limbah dari kehidupan, yang berkaitan erat dengan

p-ISSN: 2460-8815, e-ISSN: 2549-1652 jumlah manusia yang bertempat tinggal dan berusaha disuatu tempat, sebagian besar mengultimatum secara cepat, tepat, dan tegas bahwa limbah tidak patut dilihat dan dipegang, namun limbah tidak dapat diabaikan begitu saja karena limbah muncul sebagian besar karena aktifitas manusia.

Plastik adalah salah satu bahan yang kita temui dalam berbagai barang, penggunaan plastik yang tidak sesuai dengan persyaratan akan menimbulkan berbagai gangguan kesehatan, karena dapat memicu terjadinya kangker dan kerusakan jaringan pada tubuh manusia (karsinogenik). Sampah plastik jika dibakar akan mencemari udara dan jika 
sampah plastik ditimbun ditanah akan mencemari tanah dan air tanah. Plastik memiliki efek samping yang besar bagi lingkungan karena sulit terurai secara alami. Diperkirakan butuh waktu sekitar 500 sampai 1.000 tahun agar plastik bisa terurai dialam secar sempurna. Akibat lamaya plastik terurai, sehingga banyaknya sampah plastik yang berserakan sehingga mengganggu kenyamanan.

Berdasarkan uraian di atas, maka dalam penelitian ini akan dilakukan pembuatan paving block berbahan dasar sampah plastik menggunakan sistem manual dan mesin press homemade. Karakterisasi sifat mekanik paving block dilakukan dengan pengujian kuat tekan. Penelitian ini diharapkan menjadi solusi dari permasalahan sampah platik yang melimpah, sehingga dapat diolah dan dikembangkan menjadi produk yang lebih berguna dan bernilai ekonomis.

\section{METODE PENELITIAN}

\section{Metode Pengambilan Sampel}

\section{Sampah Plastik}

Sampah plastik yang digunakan limbah rumah tangga yang merupakan hsail sampah dari kegiatan sehari-hari untuk bahan utama pembuatan paving block sebagai bahan pengganti semen dan pasir. Jenis sampah yang digunakan : -PETE atau ETE (polietilen terephalate), sering sering digunakan sebagai botol minuman, minyak goreng, kecap, sambal, obat maupun kosmetik. Berlogo segitiga nomor 1.

-HDPE (High Density Polyethylen), banyak ditemukan sebagai kemasan dan obat yang tidak tembus pandang. Berlogo segitiga nomor2.

-PVC (Polyvinyl Cloride), sering digunakan sebagai produk mainan anak-anak. Berlogo segitiga nomor 3.

-LDPE (Low Density Polyethylene), biasa untuk membungkus makanan. Plastik ini berlogo segitiga nomor 4 .

-PP (Polipropilen), merupakan pelastik terbaik dan paling aman untuk yang berhubungan dangan makanan dan minuman. Plastik ini berlogo segitiga nomor 5 .

-PS (Polistirena) merupakan plastik yang hanya sesekali pakai. Contohnya adalah sterofom. Berlogo segitiga nomor 6 .
-PC (Polycarbonate), jenis plstik ini bening dan tahan panas bisa dipakai berulang kali. Plastik ini berlogo segitiga nomor 7 .

2. Sampah Organik

Sampah organik yang digunakan seperti kulit buah, daun, dan ranting. Sampah organik digunakan sebagai bahan tambahan yang dibakar langsung bersama sampah plastik.

\section{Hasil pengamatan}

Hasil pengamatan ini dilihat secara langsung dari lingkungan sekitar tempat tinggal dan tempat pembuangan akhir agar lebih jelas untuk mengetahui jenis-jenis sampah plastik atau limbah apa saja yang biasa dihasilkan dari limbah rumah tangga dalam kegiatan sehari-hari.

\section{Persiapan Alat dan Bahan}

Membuat paving block tentu membutuhkan beberap alat, baik alat moderen maupun alat tradisional. Bahanbahan dan alat yang digunakan dalam pembuatan paving block terdapat pada Tabel 1 dan Tabel 2.

Tabel 1. Bahan-bahan atau material yang digunakan.

\begin{tabular}{clcc}
\hline No & Nama Bahan & Spesifikasi & jumlah \\
\hline 1 & Sampah plastik + organik & $8 \mathrm{~kg}$ & - \\
\hline 2 & Mesin pencetakan & 2 & 1 \\
\hline 3 & Tempat pembakaran & $10 \mathrm{~kg}$ & 1 \\
\hline 4 & Korek api & - & 1 \\
\hline 5 & Sendok semen & - & 1 \\
\hline 6 & Masker & - & 1 \\
\hline 7 & Sarung tangan & - & 1 \\
\hline 8 & Air & - & - \\
\hline
\end{tabular}

(Sumber: Data Primer, 2018)

Tabel 2. Alat-alat yang digunakan

\begin{tabular}{clc}
\hline No & Nama Bahan & jumlah \\
\hline 1 & Mesin Las & - \\
\hline 2 & Mesin Gerinda & 1 \\
\hline 3 & Mesin Bor & 1 \\
\hline 4 & Mesin Milling & 1 \\
\hline 5 & Meteran & 1 \\
\hline (Sumber: Data Primer, 2018)
\end{tabular}

\section{Cara Pembuatan Paving block}

Cara pembuatan paving block dari sampah plastik Pertama-tama yang harus dilakukan masukan sampah plastik dalam tempat pembakaran, kemudian plastik dibakar ditunggu hingga meleleh, setelah meleleh dimatikan apinya dan langsung langsung masukan plastik kedalam cetakan. Apabila terlalu lama didiamkan akan menyebabkan hasil pembakaran menjadi mengeras, setelah dimasukan dalam cetakan kita press supaya menjadi padat dan tidak ada rongga 
didalam paving block, untuk mempercepat peroses pendinginan kita siram menggunakan air sehingga paving block cepet mengeras dan mendingin sehingga bisa langsung mengeluarkan paving block dari cetakan.

\section{Prosedur Pengujian}

Pada tahap ini prosedur pengujian yang dilakukan adalah melakukan pengujian kuat tekan terhadap paving block, bertujuan untuk mengetahui berapa kekuatan tekan terhadap paving block dari sampah plastik dan paving block dari sampah plastik dicampur dengan sampah organik, pada Tabel 3. dibawah merupakan komposisi sempel yang diujikan menggunakan plastik dan dicampur organik.

Tabel 3. Komposisi sampel untuk pengujian

\begin{tabular}{cccccc}
\hline No. & Material & $\begin{array}{c}\text { I } \\
\mathbf{\%}\end{array}$ & $\begin{array}{r}\text { II } \\
\mathbf{\%}\end{array}$ & $\begin{array}{c}\text { III } \\
\mathbf{\%}\end{array}$ & $\begin{array}{c}\text { IV } \\
\mathbf{\%}\end{array}$ \\
\hline 1. & Plastik & 100 & 80 & 75 & 70 \\
\hline 2. & Organik & 0 & 20 & 25 & 30 \\
\hline
\end{tabular}

\section{Rumus Perhitungan}

a. Proses Pengerasan Dicetakan

$$
\mathrm{H}=\frac{K \times A \times F t \times(T 1 \times T 2)}{L}
$$

Keterangan:

$$
\begin{aligned}
\mathrm{H} & =\text { Pemindahan kalor }(\mathrm{BTU}) \\
\mathrm{K} & =\text { Insert }(\mathrm{BTU} / \mathrm{FT}) \\
\mathrm{A} & =\text { Area total }(\mathrm{mm}) \\
\mathrm{Ft} & =\text { Filling time }(\operatorname{second}) \\
\mathrm{T} 1 & =\text { Suhu pembakaran }\left({ }^{\circ} \mathrm{C}\right) \\
\mathrm{T} 2 & =\text { Suhu awal pendinginan }\left({ }^{\circ} \mathrm{C}\right) \\
\mathrm{L} & =\operatorname{ketebalan} \text { dinding }(\mathrm{ft})
\end{aligned}
$$

Kemudian mencari $C \mathrm{t}$

$$
C \mathrm{t}=\sqrt{\frac{H}{A d \times B J_{-C} \times S h \times(T 3-T 2)}}
$$

dimana:

$$
\begin{aligned}
\mathrm{Ct} & =\text { Cooling time }(\text { second }) \\
\mathrm{Ad} & =\text { Coling hole area }(\mathrm{ft}) \\
\mathrm{Bj} \_\mathrm{c} & =\text { Density }(\mathrm{lb} / \mathrm{ft}) \\
\mathrm{Sh} & =\text { Specific heat water }(\mathrm{BTU} / \mathrm{lb}) \\
\mathrm{T} 3 & =\text { Suhu pada cetakan }\left({ }^{\circ} \mathrm{C}\right)
\end{aligned}
$$

b. Kapasitas

Rumus untuk mencri kapasitas sebagai berikut:

$Q s h=\frac{0,8 \cdot s w}{w m}$

dimana:

$$
\begin{array}{ll}
\text { Q sh } & =\text { kapasitas (pcs) } \\
\text { Sw } & =\text { kapasitas mesin produk (gr) } \\
\text { Wm } & =\text { berat produk (gr) }
\end{array}
$$

Setelah mendapatkan Q sh maka dapat mencari kapasitas dengan rumus.

$$
\begin{aligned}
& \frac{p c}{Q s h \times w m} \\
& \text { Pc } \quad=\text { pengeluaran matrial (gr) }
\end{aligned}
$$

c. Sampah yang diolah dalam Sehari

$$
\begin{array}{ll}
\frac{A X \times T X}{1000} & \\
\text { AX } \quad=\text { Total area proyeksi }(\mathrm{mm}) \\
\text { TX } \quad=\text { Tekanan yang diijinkan }(\mathrm{kg})
\end{array}
$$

d. Hasil pengujian kuat tekan

Kuat Tekan $=(\mathrm{P}) / \mathrm{L}$

dimana:

$$
\begin{array}{ll}
\mathrm{P} & =\text { beban }(\mathrm{kg}) \\
\mathrm{L} & =\text { luas bidang tekan }(\mathrm{cm} 2)
\end{array}
$$

\section{Alat Press Modifikasi}

Alat yang dibuat dengan menggunakan sistem pnenumatic yang diharapkan dengan tekanan maksimal dapat menghasilkan kuat tekan paving block yang tinggi. Alat press modifikasi ini menggunakan sistem pnenumatic untuk mengukur tekanan yang konstan, alat cetak paving block ini untuk ukuran diameter $21 \mathrm{~cm}$ dan tebal $6 \mathrm{~cm}$.

\section{HASIL DAN PEMBAHASAN Hasil Pembuatan Paving Block}

Paving block berhasil dibuat dengan bahan dasar sampah plasitk sesuai dengan prosedur penelitian yang telah dijelaskan. hasil pembuatan paving block sampah plastik dapat dilihat pada Gambar 1 Berikut.

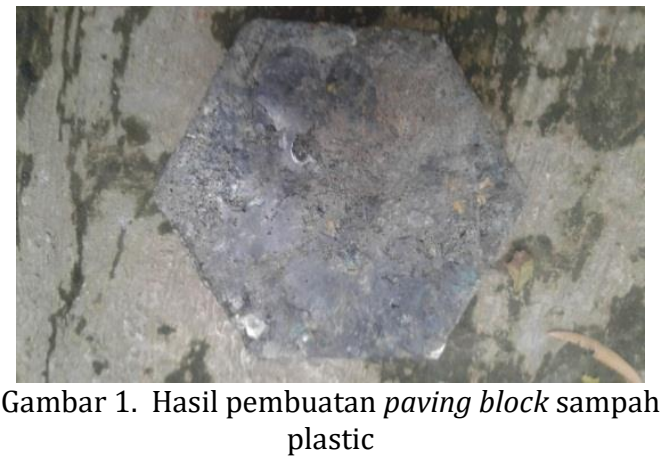

Gambar diatas merupakan paving block dari sampah plastik ada pun spesifikasinya sebagai berikut:

1) Diameter paving $21 \mathrm{~cm}$ 
2) Panjang $18,5 \mathrm{~cm}$

3) Tinggi $6 \mathrm{~cm}$

4) Berat $3 \mathrm{~kg}$

\section{Analisis dan Perhitungan}

a. Proses Pengerasan Dicetakan

Cetakan paving block ini menggunakan baja carbon, ada pun perhitunganya proses pengerasan saat dicetakan sebagai berikut.

$$
\begin{aligned}
\mathrm{H} & =\frac{K \times A \times F t \times(T 1 \times T 2)}{L} \\
& =\frac{21 \times 660 \times\left(2,124 \times 10^{-4}\right) \times(536-50)}{0,0131234 \mathrm{ft}} \\
& =12.540,860 \mathrm{BTU}
\end{aligned}
$$

Setelah mendapatkan $\mathrm{H}$ kemudian kita mencari $C \mathrm{t}$

$$
\begin{aligned}
\mathrm{Ct} & =\sqrt{\frac{\mathrm{H}}{\mathrm{Ad} \times \mathrm{BJ}_{-\mathrm{C}} \times \mathrm{Sh} \times(\mathrm{T} 3-\mathrm{T} 2)}} \\
& =\sqrt{\frac{12.540,860}{\left(5,404 \times 10^{-4}\right) \times 62,47 \times 1 \times(104-50)}} \\
& =\sqrt{2.605,822} \\
& =82,941 \text { Second }
\end{aligned}
$$

\section{b. Kapasitas}

Untuk mengetahui kapasitas yang dihasilkan dalam sekali cetak maka dari itu perlu dilakukan perhitungan, ada pun perhitunganya sebagai berikut:

$$
\begin{aligned}
Q s h & =\frac{0,8 \cdot s w}{w m} \\
& =\frac{0,8 \cdot 5000 \mathrm{gr}}{2500 \mathrm{gr}}=1,6 \mathrm{pcs}
\end{aligned}
$$

Setelah mendapatkan jumlah Q sh maka dapat mengetahuin hasil kapasitas yang dihasilkan.

$$
\frac{p c}{Q s h \times w m}=\frac{8.000}{1,6 \times 2.500}=2 p c s
$$

\section{c. Sampah yang diolah dalam Sehari}

Setelah kita tahu kapasitas dalam sekali cetak maka kita dapat mengetahui berapa jumlah sampah yang dihasilkan dalam satu hari, ada pun perhitunganya sebagai berikut:

$$
\frac{A X \times T X}{1000}=\frac{660 \mathrm{~mm} \times 5 \mathrm{~kg}}{1.000}=3,3 \mathrm{ton}
$$

\begin{tabular}{|c|c|c|}
\hline No. & $\begin{array}{c}\text { Plastik } \\
100 \%\end{array}$ & $\begin{array}{c}\text { Kuat Tekan } \\
\left(\mathrm{Kg} / \mathrm{cm}^{2}\right)\end{array}$ \\
\hline 1. & Pengujian I & 110,4 \\
\hline 2. & Pengujian II & 74,1 \\
\hline 3. & Pengujian III & 54,5 \\
\hline 4. & Pengujian IV & 42,2 \\
\hline 5. & Pengujian V & 51,6 \\
\hline \multicolumn{2}{|c|}{ Rata-rata } & 66,56 \\
\hline
\end{tabular}

\section{Hasil Pengujian Kuat Tekan}

Pengujian kuat tekan pada paving block adalah untuk mendapatkan besarnya beban tekan maksimum yang bisa diterima oleh paving block. Kuat tekan paving block dihitung dengan persamaan:

a. Hasil Pembuatan Manual

1. Hasil Pengujian paving block plastik $100 \%$

Tabel 4. Pengujian paving block plastik $100 \%$

Hasil pengujian paving block

\begin{tabular}{|c|c|c|}
\hline No & $\begin{array}{c}\text { Plastik } 80 \%+ \\
\text { Organik } 20 \%\end{array}$ & $\begin{array}{c}\text { Kuat Tekan } \\
\left(\mathrm{Kg} / \mathrm{cm}^{2}\right)\end{array}$ \\
\hline 1 & Pengujian I & 84,0 \\
\hline 2 & Pengujian II & 84,2 \\
\hline 3 & Pengujian III & 56.0 \\
\hline 4 & Pengujian IV & 90,0 \\
\hline \multirow[t]{2}{*}{5} & Pengujian V & 99,8 \\
\hline & Rata-rata & 82,78 \\
\hline
\end{tabular}
diatas dengan bahan sampah plastik $100 \%$ menunjukan nilai kuat tekan tertinggi terjadi pada pengujian pertama $110,4 \mathrm{Kg} / \mathrm{cm}^{2}$ dan nilai terendah terjadi pada pengujian keempat $42,2 \mathrm{Kg} / \mathrm{cm}^{2}$.

2. Hasil pengujian paving block plastik $80 \%$ dan organik $20 \%$

Tabel 5. Pengujian paving block plastik $80 \%$ dan organik $20 \%$

(Sumber: Data Primer, 2018)

Hasil pengujian paving block diatas dengan bahan sampah plastik $80 \%$ dan organik 20\% menunjukan nilai kuat tekan tertinggi terjadi pada pengujian kelima $99,8 \mathrm{Kg} / \mathrm{cm}^{2}$ dan nilai terendah terjadi pada pengujian ketiga $56,0 \mathrm{Kg} / \mathrm{cm}^{2}$.

Pada tabel diatas dapat dilihat nilai kuat tekan paving block dengan pembuatan manual, untuk lebih jelas dapat dilihat dari Gambar 2. 


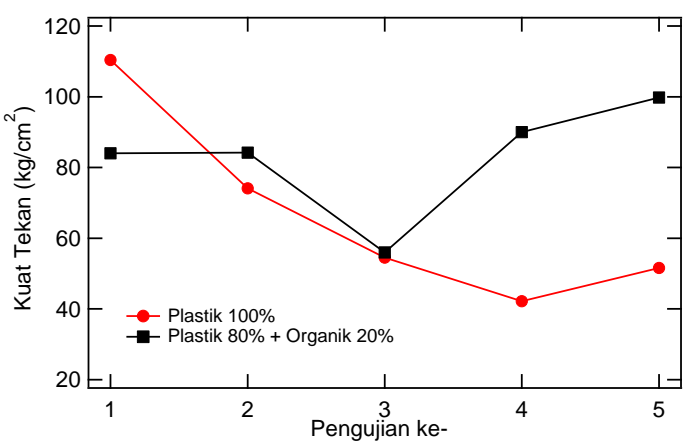

Gambar 2. Pengujian kuat tekan paving block sistem manual

b. Pembuatan Masinal

1. Hasil pengujian paving block plastik $100 \%$

Tabel 6. Pengujian paving block plastik 100\%

\begin{tabular}{|c|c|c|}
\hline No & $\begin{array}{c}\text { Plastik } \\
100 \%\end{array}$ & $\begin{array}{c}\text { Kuat Tekan } \\
\left(\mathrm{Kg} / \mathrm{cm}^{2}\right)\end{array}$ \\
\hline 1 & Pengujian I & 97,5 \\
\hline 2 & Pengujian II & 86,3 \\
\hline 3 & Pengujian III & 113,9 \\
\hline 4 & Pengujian IV & 92,6 \\
\hline 5 & Pengujian V & 78,4 \\
\hline & Rata-rata & 93,74 \\
\hline
\end{tabular}

Hasil pengujian paving block di atas dengan bahan sampah plastik $100 \%$ menunjukan nilai kuat tekan tertinggi terjadi pada pengujian ketiga $113,9 \mathrm{Kg} / \mathrm{cm}^{2}$ dan nilai terendah terjadi pada pengujian kelima 78,4 $\mathrm{Kg} / \mathrm{cm}^{2}$.

2. Hasil pengujian paving block plastik $80 \%$ dan organik $20 \%$

Tabel 7. Pengujian paving block plastik $80 \%$ dan organik $20 \%$

\begin{tabular}{|c|c|c|}
\hline No & $\begin{array}{c}\text { Plastik 80\% + } \\
\text { Organik 20\% }\end{array}$ & $\begin{array}{c}\text { Kuat Tekan } \\
\left(\mathrm{Kg} / \mathrm{cm}^{2}\right)\end{array}$ \\
\hline 1 & Pengujian I & 91,0 \\
\hline 2 & Pengujian II & 82,8 \\
\hline 3 & Pengujian III & 64,2 \\
\hline 4 & Pengujian IV & 69,0 \\
\hline \multirow[t]{2}{*}{5} & Pengujian V & 103,7 \\
\hline & Rata-rata & 87.54 \\
\hline
\end{tabular}

(Sumber: Data Primer, 2018)

Hasil pengujian paving block diatas dengan bahan sampah plastik $80 \%$ dan organik $20 \%$ menunjukan nilai kuat tekan tertinggi terjadi pada pengujian kelima $103,7 \mathrm{Kg} / \mathrm{cm}^{2}$ dan nilai terendah terjadi pada pengujian ketiga $64,2 \mathrm{Kg} / \mathrm{cm}^{2}$.
3. Hasil pengujian paving block plastik $75 \%$ dan organik $25 \%$

Tabel 8. Pengujian paving block plastik $75 \%$

\begin{tabular}{|c|c|c|}
\hline No & $\begin{array}{c}\text { Plastik 75\% + } \\
\text { Organik 25\% }\end{array}$ & $\begin{array}{c}\text { Kuat Tekan } \\
\left(\mathrm{Kg} / \mathrm{cm}^{2}\right)\end{array}$ \\
\hline 1 & Pengujian I & 98,1 \\
\hline 2 & Pengujian II & 73,2 \\
\hline 3 & Pengujian III & 69,5 \\
\hline 4 & Pengujian IV & 83,0 \\
\hline 5 & Pengujian V & 87,4 \\
\hline & Rata-rata & 82,24 \\
\hline
\end{tabular}

Hasil pengujian paving block diatas dengan bahan sampah plastik $75 \%$ dan organik $25 \%$ menunjukan nilai kuat tekan tertinggi terjadi pada pengujian pryama $98,1 \mathrm{Kg} / \mathrm{cm}^{2}$ dan nilai terendah terjadi pada pengujian ketiga $69,5 \mathrm{Kg} / \mathrm{cm}^{2}$.

4. Hasil pengujian paving block plastik $70 \%$ dan organik $30 \%$

Tabel 9. Pengujian paving block plastik $70 \%$ dan organik $30 \%$

\begin{tabular}{|c|c|c|}
\hline No & $\begin{array}{c}\text { Plastik 70\% + } \\
\text { Organik 30\% }\end{array}$ & $\begin{array}{c}\text { Kuat Tekan } \\
\left(\mathrm{Kg} / \mathrm{cm}^{2}\right)\end{array}$ \\
\hline 1 & Pengujian I & 74,0 \\
\hline 2 & Pengujian II & 56,2 \\
\hline 3 & Pengujian III & 85,4 \\
\hline 4 & Pengujian IV & 89.0 \\
\hline 5 & Pengujian V & 92,6 \\
\hline & Rata-rata & 79,44 \\
\hline
\end{tabular}

Hasil pengujian paving block diatas dengan bahan sampah plastik $70 \%$ dan organik $30 \%$ menunjukan nilai kuat tekan tertinggi terjadi pada pengujian kelima $92,6 \mathrm{Kg} / \mathrm{cm}^{2}$ dan nilai terendah terjadi pada pengujian kedua $56,2 \mathrm{Kg} / \mathrm{cm}^{2}$.

5. Hasil pengujian paving block plastik $30 \%$ dan organik $70 \%$

Tabel 10. Pengujian paving block plastik $30 \%$ dan organik $70 \%$

\begin{tabular}{ccc}
\hline No & $\begin{array}{c}\text { Plastik 30\% + } \\
\text { Organik 70\% }\end{array}$ & $\begin{array}{c}\text { Kuat Tekan } \\
\mathbf{( K g / \mathbf { c m } ^ { 2 } )}\end{array}$ \\
\hline 1 & Pengujian I & 40,8 \\
2 & Pengujian II & 36,1 \\
3 & Pengujian III & 25,3 \\
4 & Pengujian IV & 27,0 \\
5 & Pengujian V & 30,2 \\
\hline & Rata-rata & 31,88 \\
\hline
\end{tabular}

(Sumber: Data Primer, 2018) 
Hasil pengujian paving block diatas dengan bahan sampah plastik $30 \%$ dan organik $70 \%$ menunjukan nilai kuat tekan tertinggi terjadi pada pengujian pertama $40,8 \mathrm{Kg} / \mathrm{cm}^{2}$ dan nilai terendah terjadi pada pengujian ketiga $25,3 \mathrm{Kg} / \mathrm{cm}^{2}$.

6. Hasil pengujian paving block plastik $25 \%$ dan organik $75 \%$

Tabel 11. Pengujian paving block plastik $25 \%$

\begin{tabular}{|c|c|c|}
\hline No & $\begin{array}{c}\text { Plastik 25\% + } \\
\text { Organik 75\% }\end{array}$ & $\begin{array}{c}\text { Kuat Tekan } \\
\left(\mathrm{Kg} / \mathrm{cm}^{2}\right)\end{array}$ \\
\hline 1 & Pengujian I & 19,7 \\
\hline 2 & Pengujian II & 28,3 \\
\hline 3 & Pengujian III & 32,8 \\
\hline 4 & Pengujian IV & 20,0 \\
\hline \multirow[t]{2}{*}{5} & Pengujian V & 17,2 \\
\hline & Rata-rata & 23,6 \\
\hline
\end{tabular}

(Sumber: Data Primer, 2018)

Hasil pengujian paving block diatas dengan bahan sampah plastik $25 \%$ dan organik $75 \%$ menunjukan nilai kuat tekan tertinggi terjadi pada pengujian ketiga $32,8 \mathrm{Kg} / \mathrm{cm}^{2}$ dan nilai terendah terjadi pada pengujian kelima $17,2 \mathrm{Kg} / \mathrm{cm}^{2}$

7. Hasil Pengujian paving block plastik $20 \%$ dan organik $80 \%$

Tabel 12. Pengujian paving block plastik $20 \%$ dan organik $80 \%$

\begin{tabular}{|c|c|c|}
\hline No & $\begin{array}{l}\text { Plastik 20\%+ } \\
\text { Organik 80\% }\end{array}$ & $\begin{array}{c}\text { Kuat Tekan } \\
\left(\mathrm{Kg} / \mathrm{cm}^{2}\right)\end{array}$ \\
\hline 1 & Pengujian I & 22,4 \\
\hline 2 & Pengujian II & 20,1 \\
\hline 3 & Pengujian III & 14,0 \\
\hline 4 & Pengujian IV & 9,5 \\
\hline 5 & Pengujian V & 16,2 \\
\hline \multicolumn{2}{|c|}{ Rata-rata } & 16,2 \\
\hline
\end{tabular}

Hasil pengujian paving block diatas dengan bahan sampah plastik 20\% dan organik $80 \%$ menunjukan nilai kuat tekan tertinggi terjadi pada pengujian pertama $22,4 \mathrm{Kg} / \mathrm{cm}^{2}$ dan nilai terendah terjadi pada pengujian keempat $9,5 \mathrm{Kg} / \mathrm{cm}^{2}$.

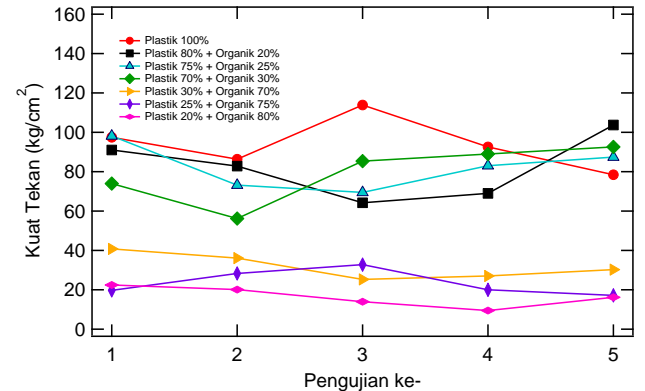

Gambar 3. Pengujian kuat tekan paving block sistem press

Grafik diatas menunjukan dari hasil pengujian paving block pembuatan masinal.

\section{Hasil Penelitian}

Dari hasil penelitian antara metode manual, mesin press, dan dengan yang ada dipasaran, paving block dengan plastik 100\% yang dibuat dengan mesin press lebih besar sifat mekaniknya, dapat dilihat pada tabel 13, 14, dan 15.

\begin{tabular}{|c|c|c|}
\hline No. & $\begin{array}{c}\text { Pembuatan } \\
\text { Manual }\end{array}$ & $\begin{array}{c}\text { Kuat Tekan } \\
\left(\mathrm{Kg} / \mathrm{cm}^{2}\right)\end{array}$ \\
\hline 1 & Pastik 100\% & 66,56 \\
\hline 2 & $\begin{array}{l}\text { Plastik } 80 \% \text { \& } \\
\text { organik } 20 \%\end{array}$ & 82,78 \\
\hline
\end{tabular}

Tabel diatas adalah tabel rata-rata dari hasil pengujian kuat tekan paving block dari pembuatan manual.

\begin{tabular}{clc} 
Tabel 14. Pengujian paving block manual \\
\hline No. & $\begin{array}{c}\text { Pembuatan } \\
\text { Masinal }\end{array}$ & $\begin{array}{c}\text { Kuat } \\
\text { Tekan } \\
\text { (Kg/cm }\end{array}$ \\
\hline 1 & Plastik 100\% & 93,74 \\
\hline 2 & $\begin{array}{l}\text { Plastik 80\% \& } \\
\text { organik 20\% }\end{array}$ & 87,54 \\
\hline 3 & $\begin{array}{l}\text { Plastik 75\% \& } \\
\text { organik 25\% }\end{array}$ & 82,24 \\
\hline 4 & $\begin{array}{l}\text { Plastik 70\% \& } \\
\text { organik 30\% }\end{array}$ & 79,44 \\
\hline 5 & $\begin{array}{l}\text { Plastik 30\% \& } \\
\text { organik 70\% } \\
\text { Plastik 25\% \& } \\
\text { organik 75\% } \\
\text { Plastik 20\% \& } \\
\text { organik 80\% }\end{array}$ \\
\hline Sumber: Data Primer 2018)
\end{tabular}

(Sumber: Data Primer, 2018)

Tabel diatas adalah tabel rata-rata dari hasil pengujian kuat tekan paving block dari pembuatan masinal. 
Tabel 15. Paving block dipasaran

\begin{tabular}{clc}
\hline No. & $\begin{array}{c}\text { Pembuatan } \\
\text { Masinal }\end{array}$ & $\begin{array}{c}\text { Kuat Tekan } \\
\left(\mathbf{K g} / \mathbf{c m}^{2} \mathbf{)}\right.\end{array}$ \\
\hline 1 & Karya Indah & 44,05 \\
\hline 2 & Sinar Mulya & 18,55 \\
\hline 3 & Buana & 14,52 \\
\hline 4 & Paving Lestari & 39,09 \\
\hline 5 & Anisa & 47.04 \\
\hline
\end{tabular}

Tabel diatas adalah tabel rata-rata dari hasil pengujian kuat tekan paving block dari pasaran.

\section{KESIMPULAN}

\section{Kesimpulan}

1. Kepadatan dalam proses pembuatan benda uji sangat mempengaruhi nilai kuat tekan yang dihasilkan. Hal ini dibuktikan bahwa masih ada rongga udara dalam paving block pembuatan manual.

2. Hasil dari penelitan paving block pembuatan manual dengan 100\% sampah plastik, nilai tertinggi 110,4 $\mathrm{Kg} / \mathrm{cm}^{2}$ dan terendah $42,2 \mathrm{Kg} / \mathrm{cm}^{2}$ dan pada campuran organik nilai tertinggi $99,8 \mathrm{Kg} / \mathrm{cm}^{2}$ dan terendah $56,0 \mathrm{Kg} / \mathrm{cm}^{2}$. Sedangkan pada pembutan masinal menghasilkan nilai dengan $100 \%$ sampah plastik 113,9 $\mathrm{Kg} / \mathrm{cm}^{2}$ nilai terendah $78,4 \mathrm{Kg} / \mathrm{cm}^{2}$ dan mengalami penurunan saat pemberian organik.

3. Sebagai solusi yang tempat untuk permasalahan limbah plastik, karena setelah dibuat paving block yang digunakan untuk bahan bangunan maka jumlah sampah akan berkurang.

\section{Saran}

1. Lakukan pra uji sebelum melakukan pengujian supaya memperkecil tingkat kesalahan.

2. Untuk mengetahui tingkat kepadatan dari paving block ini perlu kaji kembali mengenai alat yang digunakan, baik menggunakan mesin press pneumatic atau pun dengan alat cetak paving block manual.

3. Perlu dilakukan penelitian lebih lanjut untuk mengetahui nilai kuat tekan paving block sesui standar SNI.

\section{DAFTAR PUSTAKA \\ Artikel Jurnal}

Budi Haryanto. 2015. Pengen dalian Kualitas Beton Dengan Pengujian Kuat Tekan.

Cheongmyun, 2011. Ancaman Polymer Bagi Kesehatan Manusian.

Keni Vidilaseris. 2014. Mengapa Plastik Tidak Bisa Terurai Dengan Cepat.

Nurhenu Karuniastuti, 2015. Bahaya Plastik Terhadap Kesehatan Dan Lingkungan.

Pramiati Purwaningrum. 2016. Upaya Mengurangi Timbulan Sampah Plastik Dilingkungan, 141-147.

Prayitno \& Sukosono. 2016.

Reduksi Limbah Padat Dengan Sistem Pembakaran Dalam Tungku Ruang Bakar, 61.

Rina Kwartiana. 2015. Kode Plastik Dan Jenisny.

Syukur s \& I Wayan D, 2011. Perbandingan Mutu Paving block Manual Dengan Masinal.

Tri Wahyuni. 2015. Berapa Lama Sampah Plastik Bisa Terurai.

Zakka, 2013. Sifat Fisik Matrial. 
